of the properties of steel with the carbon content and the influence of nickel, manganese, vanadium, chromium, etc. The author gives a general theory of the heat treatment of steels which is original, and which, the author believes, throws much light on practical problems and is certainly interesting. Cements are shortly treated in a final chapter.

Although some defects; probably due to haste, have been indicated, this treatise is really a good one and can be recommended to practical engineers as containing information not easily accessible elsewhere. Perhaps the fault of being rather too positive in accepting conclusions not fully established is one to which a teacher of students is specially liable.

\section{SOUND ANALYSIS.}

The Science of Musical Sounds. By Prof. D. C. Miller. Pp. viii +286 . (New York: The Macmillan Company; London : Macmillan and Co., Ltd., I9ı6.) Price ıos. 6d. net.

TNDER the above title the author has presented in book form a series of eight lectures on sound analysis delivered at the Lowell Institute in January and February, I9I4. A course of scientific lectures designed for the general public must consist in large part of elementary and well-known material, selected and arranged to develop the principal line of thought. But it is expected that lectures under the auspices of the Lowell Institute, however elementary their foundation, will present the most recent progress of the science in question. It is further expected that such lectures will be accompanied by experiments and illustrations to the greatest possible degree.

Thus, in the present work, we find that mathematical treatment is almost absent; the few equations that occur throughout its pages might be collected so as to appear at a single opening of the book. On the other hand, the figures number nearly two hundred, many of them being photographic reproductions of vibration curves or apparatus. These serve to indicate the wealth of the demonstrative material by which the lectures were illustrated.

The first lecture deals with sound-waves, simple harmonic motion, noise, and tone; the second with the characteristics of tones. The third lecture is concerned with methods of recording and photographing sound-waves, and includes a description of the author's special recorder called the phonodeik. Lectures four and five develop the analysis and synthesis of compound harmonic curves, and treat the influence of horn and diaphragm. The sixth and seventh lectures are concerned with the tone qualities of musical instruments and the physical characteristics of the vowels. The eighth lecture treats the problems of the synthesis of vowels and words, and concludes with remarks on the relations of the art and science of music.

The work includes a valuable bibliographic NO. 2443, VOL. 97 ] appendix of more than a hundred references. The type and illustrations are large and clear, and the book should prove welcome to a wide circle of readers and find an honoured place in every acoustical library.

E. H. B

\section{OUR BOOKSHELF.}

Studies in Blood-Pressure, Physiological and Clinical. By Dr. George Oliver. Edited by Dr. W. D. Halliburton. Pp. xxiii +240 . Third edition. (London: H. K. Lewis and Co., Ltd., I9r6.) Price $7 s .6 d$. net.

THIS posthumous edition opens with an obituary notice of the author by Prof. Halliburton, who has undertaken the duties of editor as a "true labour of affection and respect." This latest edition embodies the chief advances in the clinical investigation of blood-pressure, and contains a description of the author's own instruments for testing the pressure. It is argued that the condition of the vessel wall does not seriously interfere with correct readings; hypertonicity, which produces the greatest resistance, can be counteracted by repeated compression or massage. It is noteworthy that occupations involving anxiety, worry, and nerve strain tend to augment blood-pressure. It is pointed out that "pulse-pressure" (the difference between the systolic and the diastolic pressure) tends to increase after the age of forty. The suggestion that arterio-sclerosis may be so advanced as to cause an entire abolition of vasomotor control is open to question; for it is difficult to see how life could be carried on under such conditions. The author holds that widespread thickening of the arterial wall suffices to maintain long-continued high pressure, and that there is no need to postulate persistent hypertonicity of the arteries, which he considers physiologically improbable.

The Chemistry of the Garden: A Primer for Amateurs and Young Gardeners. By Herbert $\mathrm{H}$. Cousins. Revised edition. Pp. xviii $+\mathbf{r} 43$. (London: Macmillan and Co., Ltd., I9r6.) Price I $s$.

WHEN the demand for a book is such that it needs to be reprinted eight times since its first issue in I898 and now calls for a revised edition, it obviously needs little commendation to the public for whom it is written. Mr. Cousins's volume contains in its 143 pages a vast amount of information on the management of soil for the successful production of garden crops. In the new edition we notice reference to recent Rothamsted work on partial sterilisation and to the shortage of potash caused by the war. On the latter account the gardener need not worry, as any moderately good garden soil has ample reserves of potash, which can be made available as plant food by suitable treatment. We do not agree with two of the author's remarks on dung. He says that "no analysis is of much value": on the contrary, experience at Rothamsted and elsewhere shows that 